\title{
El Gabinete de lectura del Ateneo Mexicano
}

\section{Ateneo Mexicano's Reading Cabinet}

JOCELYN GUADALUPE LÓPEZ ZAHAR

https://orcid.org/0000-0001-5877-0663

Colegio de Historia (Facultad de Filosofía y Letras)

Universidad Nacional Autónoma de México

jocelyn.lopez.zahar@gmail.com

\section{RESUMEN}

El Ateneo Mexicano, una de las primeras asociaciones literarias del México independiente, fue creado para favorecer la instrucción pública del joven pais. La institución tuvo su propio Gabinete de lectura. Un inventario de libros donados al Museo Nacional de México muestra qué impresos tenia la biblioteca del Ateneo, mismo que fue reconstruido y se presenta en este artículo para dar a conocer una valiosa fuente de información que denota la variedad temática de los libros, en relación con las materias de las cátedras impartidas por los ateneístas.

Palabras clave: Ateneo Mexicano, asociación literaria, Gabinete de lectura, biblioteca, instrucción pública.

\section{ABSTRACT}

The Ateneo Mexicano, one of the first literary society in independent Mexico, was created to promote public education in that young country. The institution had its own Reading Cabinet. An inventory of books donated to the National Museum of Mexico shows that what kind of printed materials use to had the Ateneo's library. That inventory was reconstructed and is presented in this article to reveal an important source of information, it shows the thematic variety of books, concerning with all topics of the classes given by Ateneo's members.

Keywords: Ateneo Mexicano, literary society, Reading Cabinet, library, public instruction.

hISTORICn XLV.1 (2021): 155-183 / e-ISSN 2223-375X 


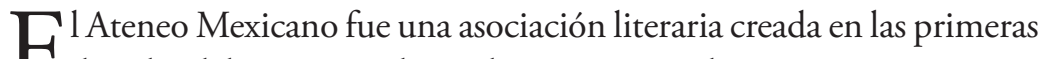
décadas del México independiente. Para explicar sus características, es necesario describir el contexto en que fue creado. Bajo la corriente ilustrada dieciochesca, se resaltó la importancia del conocimiento y se crearon instituciones educativas en el Viejo Continente. Ese pensamiento no fue exclusivo de Europa, porque influyó en los letrados novohispanos y prevaleció tras la independencia de México, nación en la que se propuso impulsar a la instrucción pública como un signo de modernidad. ${ }^{1}$

Tanto el interés por educar a la población como la creciente necesidad de escribir una historia nacional motivaron al Estado mexicano a crear asociaciones literarias: la Sociedad de Amigos del País (1822-1823), la Sociedad de Literatos (1831-1833) y el Liceo Mexicano, Artístico y Literario (1835), las cuales funcionaron por poco tiempo debido a la inestabilidad política y económica del país. ${ }^{2}$ En estas, participaron diversos profesionistas, desde científicos hasta poetas, ${ }^{3}$ quienes aspiraban que México ocupara un lugar importante en el mundo de las letras y, de ese modo, reforzar las relaciones exteriores del país y, por ende, mejorar sus alianzas políticas y económicas. ${ }^{4}$ Así que persistió el interés de los letrados por crear más instituciones educativas. Una de ellas fue el Ateneo Mexicano, inspirado en las asociaciones literarias homónimas.

El Athenaeum, fundado en Londres (1824), fue la primera asociación literaria con ese nombre. ${ }^{5}$ A lo largo del siglo XIX, se crearon varios ateneos en España y otras latitudes europeas. Eran espacios recreativos para educar a las personas de las clases populares. ${ }^{6}$ El Ateneo de Madrid fue uno de los más importantes y sirvió como modelo a seguir para el caso mexicano. El Ateneo Español, fundado en 1820 y reabierto en 1835 bajo el nombre Ateneo de Madrid, fue una academia científica organizada en varias secciones: Ciencias Morales y Políticas, Ciencias Naturales, Cien-

1 Urías 1988: 32.

2 Colon 2009: 93; Azuela 2018: 37; Urías 1988: 29-30.

3 Azuela 2018: 37.

4 Urías 1988: 41.

5 Villacorta 2003: 425.

6 Arnabat Mata 2012: 391. 
cias Matemáticas y Literatura y Bellas Artes. Ahí, se impartían cátedras públicas y gratuitas de esas materias para fomentar el desarrollo científico. $^{7}$ A diferencia de las sociedades económicas españolas, en el Ateneo de Madrid se prestó más atención a los temas políticos y científicos que a los económicos; además, se dio mayor importancia al departamento de Ciencias Históricas, porque se pretendía consolidar el discurso histórico nacional para fortalecer la identidad del disgregado Imperio español. ${ }^{8}$

La creación de ateneos se expandió por otros territorios europeos y americanos. Fue así que José Gómez de la Cortina, diplomático y aclamado escritor mexicano que se unió a la Real Sociedad Económica de Valencia, estuvo familiarizado con las instituciones españolas de instrucción pública, tales como el Ateneo de Madrid. ${ }^{9}$ Gómez de la Cortina fue allegado a políticos mexicanos: el reconocido poeta, político y escritor Andrés Quintana Roo; Juan Nepomuceno Almonte, destacado político e hijo del prócer de la patria José María Morelos y Pavón; entre otros que se reunieron con Ángel Calderón de la Barca (primer ministro de España) el 5 de diciembre de 1840 en la sala rectoral del extinto Colegio de Santa María de Todos los Santos y acordaron crear un ateneo en México. ${ }^{10}$

Como se ha señalado, el Ateneo Mexicano se inspiró en la asociación literaria de Madrid, por lo que tuvo la misma organización interna, así como manejo de sus fondos: su misión fue amenizar la instrucción pública mexicana para favorecer la educación en diversos ramos científicos, introducir al país los métodos de enseñanza europeos y satisfacer las demandas de la población. Por consiguiente, los ateneístas priorizaron fomentar el conocimiento científico e impartir cátedras, según indicaba su reglamento provisional. ${ }^{11}$

Las actividades del Ateneo empezaron el 6 de diciembre de 1840. La más importante fue la impartición de cátedras de historia, literatura,

7 Villacorta 2003: 416-421.

8 Sánchez 1892-1893: 129-136.

9 De la Guardia 2005: 10.

${ }^{10}$ Perales 2017.

${ }^{11}$ Urías 1988: 42-46. 
geografía, legislación, industria, ciencias morales e idiomas, que se iniciaron en las primeras semanas de enero de 1841 en un local ubicado en la calle Espíritu Santo No. 8 (actualmente, Isabel la Católica,), pero los encargados del Ateneo lo dejaron y pidieron prestado un salón a la Universidad de México, ${ }^{12}$ ya que no contaban con presupuesto suficiente para pagar la renta o financiar un edificio propio; así que solicitaron un espacio que los universitarios no ocuparan. ${ }^{13}$

En ese inmueble, estaban otras instituciones republicanas: la Biblioteca Nacional y el Museo Nacional, este último ocupaba dos salones en la planta alta, contiguos al que fue asignado al Ateneo. En ese mismo piso, también se encontraba la biblioteca universitaria, una de las más importantes de la capital. ${ }^{14}$ Como los ateneístas tenían claro que esa asociación literaria sería útil para la instrucción pública, desde sus inicios plantearon establecer su propio Gabinete de Lectura. ${ }^{15}$ Beatriz Urías indicó que el acervo se formó «con donaciones particulares y con la mitad del acervo de la biblioteca del Estado de México, cedida por el gobierno», ${ }^{16}$ hecho que fue dado a conocer en el periódico El Siglo Diez y Nueve. ${ }^{17}$ Además, un autor anónimo indicó que la donación y el traslado del acervo bibliográfico del ex Colegio de Santa María de Todos los Santos al Ateneo habría beneficiado en gran medida a este último, pero no se llevó a cabo. ${ }^{18}$

En vista de la falta de espacio, el salón que ocupaba el Ateneo sirvió como salón de clases y biblioteca. En esa aula, se hacían exámenes a los estudiantes ateneístas ${ }^{19}$ y a los de otros colegios, como los del instituto de Nuestra Señora del Refugio, por mencionar un ejemplo. ${ }^{20}$ Además, este fue el espacio de reunión de los encargados de la institución. ${ }^{21}$

\footnotetext{
${ }^{12}$ Ib.: 43.

${ }^{13}$ Gómez de la Cortina 1842: 476.

${ }^{14}$ Suárez 2020:144.

${ }^{15}$ Velez. 1842: 3.

${ }^{16}$ Urías 1988: 43.

${ }^{17}$ Zirea y Gómez de la Cortina 1841: 2.

${ }^{18}$ Mexicano 1843: 3.

${ }^{19}$ Anónimo. 1843c: 275.

${ }^{20}$ Esteban 1843: 2.

${ }^{21}$ Anónimo. 1843b: 256.
} 
Reconocidos miembros de la República de las Letras impartieron las cátedras para fomentar la instrucción pública y favorecer el aprendizaje por medio de la lectura: ciencias morales, Miguel Valentín; botánica y agricultura, Miguel Bustamante; historia, José María Bocanegra; literatura, Manuel Moreno Jove; geografía, Gómez de la Cortina; legislación, Manuel de la Peńa y Peńa; idiomas, Lucas Alamán; industria, Ignacio Cumplido; fomento del Ateneo, Juan N. Gómez de Navarrete, y de redacción del periódico de la asociación el señor don Andrés Quintana Roo. ${ }^{22}$

En 1841, se dieron inicio a las clases de historia y de pintura, aunque estas se suspendieron por algún tiempo. ${ }^{23}$ Se desconoce cuándo se reabrieron, pero habría sido en octubre de ese mismo año. ${ }^{24}$ Una nota del Semanario de Industria Mexicana, en la que se exigía al gobierno brindar al Ateneo la protección que habían tenido otras instituciones de instrucción pública, ${ }^{25}$ indica que, a pesar de las dificultades económicas y la falta presupuestal, hubo interés por mantener en pie a la institución. Se tiene noticia de un curso de geografía dado en $1842,{ }^{26}$ así como de una de español que no se pudo llevar a cabo por falta presupuestal, pues en febrero de ese año, por medio de la prensa, se invitaba a los lectores a donar dinero a Gómez de la Cortina a efecto de impartir esa cátedra. ${ }^{27}$ Efectivamente, en 1842, el gobierno no destinó dinero suficiente al Ateneo y a otras instituciones de instrucción pública mexicanas (como la Biblioteca Nacional). ${ }^{28}$

El 10 de abril de 1843, en el Diario del Gobierno de la República Mexicana, se anunció la inauguración de la sala de lectura del Ateneo Mexicano, la cual sería el domingo de Pascua de ese año y, ese mismo día, se publicó el reglamento de la institución, tema que fue propuesto

22 Perales 2017.

${ }^{23}$ Anónimo 1849: 99; Vergara 1841: 4.

24 Bergara 1841: 4.

${ }^{25}$ Anónimo 1841: 70.

${ }^{26}$ Zurutuza y De Veraza 1842: 4.

${ }^{27}$ El observador 1842: 2.

${ }^{28}$ E.E. de la Hesperia 1842: 391. 
por José María Tornel (ministro de guerra) en la junta general. ${ }^{29} \mathrm{El}$ salón estaría abierto desde el 16 del mismo mes, «de nueve de la mañana, hasta las tres de la tarde, y desde las seis de esta hasta las nueve de la noche». ${ }^{30}$ El 2 de agosto de 1843 se abrió una cátedra de francés en el Ateneo, ${ }^{31}$ lo cual podría sugerir una mejora en las condiciones de la institución que, pese a los problemas presupuestales y la reducción del salario de los profesores, ${ }^{32}$ siguió en pie. Además, el 12 de noviembre de 1843 se anunció el cambio de encargado del Ateneo y se presentó a Tornel como una persona altamente calificada que daría mayor protección y solidez a la institución. ${ }^{33}$ En una nota publicada el 15 de noviembre de 1844 , en el Siglo Diez y Nueve, se expuso la precariedad de los gabinetes de lectura de la joven nación mexicana, incluyendo al Ateneo: «En México no hay liceos. El Ateneo da pocas señales de vida; los gabinetes de lectura no se han podido aclimatar; y en cuanto a la librería, su comercio, en un tiempo lucrativo, es hoy insignificante». ${ }^{34}$

Si bien por mucho tiempo el salón que ocupaba el Ateneo fue un espacio idóneo para las cátedras de los ateneístas y algunas universitarias, ${ }^{35}$ es necesario considerarlo también como un espacio de prácticas lectoras, ya que desde 1844 ahí se llevaron a cabo algunas lecturas públicas. Todo empezó en una junta de los organizadores de esa institución, efectuada el 21 de enero de ese ańo, en la cual se estableció que «sobre la apertura de cátedras, cada sección está obligada a presentar [...] memorias, lecturas o esposiciones los jueves de cada semana». ${ }^{36}$

En otra junta general celebrada el 18 de febrero de 1844, se aceptó la propuesta de realizar diez lecturas públicas sobre el pasado mexicano para promover su estudio, mismas que tratarían sobre la conquista, el gobierno español en las tierras americanas, la evangelización y el combate

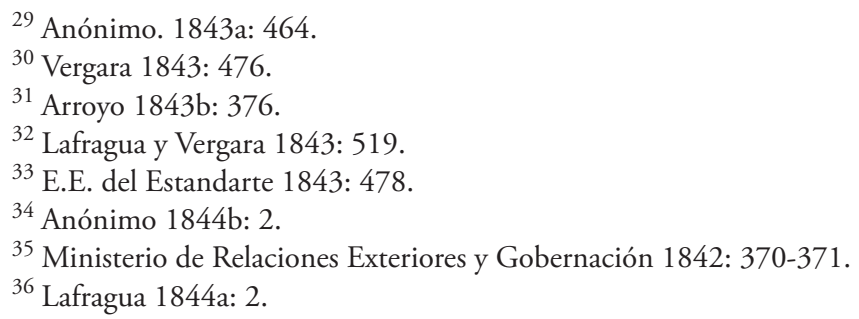


a la idolatría, la vida de Hernán Cortés, la administración pública del virreinato, las obras del desagüe de Huehuetoca, la construcción de la Catedral Metropolitana, la dinastía borbónica, el gobierno de José de Gálvez y las causas de la independencia de México. ${ }^{37}$

El 25 de febrero de 1844, se inauguró el programa de «lecturas públicas del Ateneo Mexicano», evento que tuvo gran concurrencia, porque el proyecto fue visto como un paso importante para el estudio de las artes y de las ciencias. En la inauguración, Tornel pronunció un discurso que resaltó que la importancia del fomento de las letras públicas. ${ }^{38}$ Además de las lecturas de historia ya señaladas, se llevó a cabo otras sobre ciencias naturales por Miguel Bustamante; ciencias militares por José María Tornel; ciencias morales por Ignacio Vera; ciencias médicas por Manuel Carpio; instrucción primaria por Rafael Espinoza; lengua castellana por José Gómez de la Cortina; idiomas por Camilo Bros; ${ }^{39}$ industria por Mariano Gálvez, ${ }^{40}$ geografía por Pedro García Conde y literatura por Luis de la Rosa, Mariano Otero, José María Lacunza y Manuel Payno. ${ }^{41}$

Paralelamente a la ejecución del programa de lecturas públicas, los miembros del Ateneo Mexicano editaron una revista con el mismo nombre, en la que se trataban temas de las mismas materias que sus cátedras. ${ }^{42} \mathrm{Su}$ primer número fue publicado el 15 de marzo de $1844 .{ }^{43}$ Se puede inferir que tener libros era fundamental para realizar las lecturas públicas y las publicaciones, por lo que hay que dar mayor peso al Gabinete de Lectura de los ateneístas al investigar a esa institución.

Rafael Isidro Gondra trabajó como bibliotecario en el Gabinete de Lectura desde $1845 .{ }^{44}$ Él estuvo involucrado en las tareas del Museo Nacional, pero en sus publicaciones de periódicos se identificaba como miembro del Ateneo Mexicano, como puede verse en su escrito «El

\footnotetext{
${ }^{37}$ Lafragua 1844c: 3; Alamán 1844: 259.

38 Anónimo. 1844a: 243.

${ }^{39}$ Lafragua 1844d: 4.

${ }^{40}$ Ateneo Mexicano 1844: 382.

${ }^{41}$ Lafragua 1844b: 4.

42 Urías 1988: 47.

${ }^{43}$ Ateneo Mexicano 1848: 340.

${ }^{44}$ Anónimo. 1845: 4.
} 
orador es el púlpito-Elocuencia sagrada». ${ }^{45}$ Quizá se desempeñó como bibliotecario porque estaba interesado en ganar prestigio y mérito con esa labor, tal como sucedía con los bibliotecarios de finales del siglo XVIII. ${ }^{46}$

En definitiva, es posible caracterizar a la institución como un centro educativo y, a la vez, como un espacio laico en el que hubo prácticas lectoras, a comparación de las bibliotecas de colegios y conventos que solían ser los espacios de lectura por excelencia, a decir de Kenya Bello. ${ }^{47}$ Lo dicho hasta aquí supone que podría estudiarse la historia de la lectura en el Ateneo. No hay que enfocarse solo en las lecturas públicas, sino también contemplar las lecturas de quienes consultaban el acervo bibliográfico. Un primer paso para abordar este tema es conocer, con mayor exactitud, qué libros había en ese gabinete de lectura, a lo que podemos acercarnos gracias a un inventario de libros elaborado el $1 \mathrm{de}$ diciembre de $1849 .{ }^{48}$

Para empezar, es necesario recalcar que desde 1845, el Ateneo tuvo un declive (se desconoce con exactitud qué lo causó, porque hay pocas noticias sobre las actividades en el Ateneo a partir de 1846) ${ }^{49}$ que llevó a su desaparición en 1847, el mismo año en que ocurrió la invasión norteamericana a México. Dos años después del cierre de la institución, en diciembre de 1849, se hizo un inventario y se determinó que los libros del Gabinete serían donados al Museo Nacional. Este hecho quizá se deba a que hubo una estrecha relación entre los ateneístas y los trabajadores del recinto; así, por ejemplo, Gondra había sido bibliotecario del Ateneo y, a su vez, fue conservador del museo entre 1835 y $1852 .{ }^{50}$ Este inventario de bienes de la asociación se trata de una fuente de información que

\footnotetext{
${ }^{45}$ Gondra 1844: 152.

${ }^{46}$ Cortéz. 2019: 98.

47 Bello 2017: 215-248.

${ }^{48}$ Inventario de las obras pertenecientes al Estado de México que existían en el Ateneo y que ha entregado el Señor Don Ysidro Rafael Gondra. Ciudad de México, de 1 de diciembre de 1849. AHMNA, Museo Nacional de México, vol. 1, exp. 10, ff. 38-43.

${ }^{49}$ Se desconoce la vida del Ateneo entre 1846 y 1850, es probable que se hayan suspendido las reuniones entre los ateneístas por la difícil situación política y económica que atravesaba el país. Véase Urías 1988: 45.

${ }^{50}$ Arroyo 1843a; 127; Lahirigoyen 2005: $7 .$.
} 
ofrece un panorama general de todo el acervo bibliográfico que formó en su corto tiempo de vida.

El expediente consta de cinco fojas escritas por ambos lados y contiene: 1) el inventario de las obras que pertenecieron a la biblioteca del Ateneo de México y pasaron al Museo (103 títulos en 737 volúmenes); 2) una lista de los mapas y libros que el Estado de México donó al recinto (5 títulos en 22 libros,), así como el donativo hecho por el Hospicio de San Agustín de las Cuevas (12 títulos en 19 libros,) y 3) un registro de las obras pertenecientes a Gondra (4 títulos en 8 libros). En la lista, los libros aparecen ordenados alfabéticamente por nombre de autor; en algunos casos, se indica el tipo de encuadernación, pero no el formato, el lugar de edición, el nombre del impresor o del taller. Se puede inferir que quien revisaba el estante y registraba, o dictaba a alguien más, conocía varios idiomas, ya que en el inventario aparecen en español los títulos de algunas publicaciones extranjeras que en ese entonces no estaban traducidas al castellano. La segunda y tercera parte del inventario tiene las mismas características, con excepción del orden alfabético, lo cual no era necesario porque eran pocos los libros donados.

El orden alfabético de los libros en los inventarios suele corresponder con su ubicación en los estantes. Este criterio de ordenamiento era usado en las grandes librerías comerciales, ${ }^{51}$ y también algunas bibliotecas decimonónicas estaban acomodadas de esa manera, por ejemplo, la biblioteca de Santiago de Compostela en España, de la cual se elaboró un índice alfabético de autores. ${ }^{52} \mathrm{El}$ inventario indica que todos los libros tenían cubiertas doradas. Este tipo de encuadernación era ornamental: se trata de una técnica usada para fijar un diseño con oro en lámina o papel sobre la cubierta o el lomo del libro, lo cual muestra la dedicación que el personal del Ateneo puso en los libros de su Gabinete.

La información sobre los libros no es del todo precisa, ya que se indica el número de tomos, seguido del nombre del autor (empezando por su apellido la mayoría de las veces) y el título de la obra, mas no se indica

${ }^{51}$ Suárez 2014: 185-200.

52 García López y López Álvarez 2004: 66. 
el lugar, año de impresión, imprenta y formato. Para la identificación de los títulos de los libros, me he servido de diversos catálogos digitales de bibliotecas mejicanas y europeas. ${ }^{53}$ Con miras a que la reconstrucción se acerque lo mejor posible a las ediciones que había en el Gabinete de Lectura del Ateneo, se procuró que las ediciones no sobrepasaran el año en que se produjo el inventario (1848). Ese fue un criterio esencial durante la búsqueda.

Finalmente, se optó por transcribir el documento respetando la ortografía original y la distribución del texto. Cada entrada tiene su referencia bibliográfica correspondiente con los siguientes datos: Nombre del autor, título de la obra, no. de volúmenes, no. de edición, lugar de impresión, imprenta, año [formato].

Si bien algunos aspectos del Ateneo han sido estudiados, como su asociación de geografía que fue examinada por Ana Lilia Sabas, ${ }^{54}$ en este trabajo se plantea que el Ateneo Mexicano tuvo una variada biblioteca, cuyos temas se relacionan con las materias impartidas en las cátedras de los ateneístas. Es importante analizar la variedad de títulos de cada materia para aproximarnos a las preferencias de los estudiantes de esa institución, ya que el inventario permite conocer qué tipos de obras eran de su interés y, a su vez, identificar las diferencias entre el contenido de este acervo bibliográfico y los de los antiguos colegios coloniales, en los que predominaba la literatura religiosa.

Para empezar, el contenido de la biblioteca del Ateneo Mexicano puede clasificarse en materias, mismas que fueron impartidas en las cátedras de esa institución: de un total de 103 títulos distintos (737 ejemplares), 31 eran de historia, 31 de jurisprudencia y ciencias morales, 18 de literatura

${ }^{53}$ Catálogos digitales de la Biblioteca Nacional, Biblioteca Ernesto de la Torre Villar (Instituto Dr. José María Luis Mora); Biblioteca Nacional de Antropología e Historia: Eusebio Dávalos Hurtado (Instituto Nacional de Antropología e Historia); Biblioteca Digital Hispánica (Biblioteca Nacional de Espańa); Biblioteca virtual de las Letras Mexicanas; Biblioteca virtual Miguel de Cervantes; portal Hathi Trust Digital Library; portal Archive.org; portal Academia Colecciones; portal Open Editions; Universal Short Title Catalogue; portal Europeana y el Catálogo Colectivo del Patrimonio Bibliográfico Espańol.

${ }^{54}$ Sabas 2010: 91-129. 
e idiomas, 11 de ciencias (exactas), 4 de industria, 3 de religión, 2 de agricultura y 3 sin determinar. Con base en la cantidad de títulos de historia y jurisprudencia, es probable que estas dos materias hayan sido de mayor interés que las demás.

En cuanto las obras históricas, por una parte, trataban sobre el pasado europeo, en especial de España o Francia, como las Memorias de las reynas catholicas, historia genealógica de la casa real de Castilla, y de León, escrita por Enrique Flores, destacado escritor de la historia eclesiástica española y de la antigüedad, o las Reflexiones sobre la revolución de Francia; del británico Edmund Burke. Por otro lado, hubo libros sobre la nación mexicana, como la Historia antigua de Megico, redactada por Francisco Xavier Clavijero. Además, algunas obras del inventario retoman la numismática, es el caso de Medallas de las colonias, municipios y pueblos antiguos de España, del ya mencionado Enrique Flores. Así como en el Ateneo de Madrid hubo un creciente interés por forjar un discurso nacional, en la institución mexicana se priorizó a la historia para promover su estudio, tal como se refleja en la gran cantidad de obras históricas referidas en el inventario y en el programa de lecturas públicas sobre diversos acontecimientos del pasado del país, el cual ha sido referido anteriormente.

En cuanto a la jurisprudencia hubo libros sobre las leyes de otros países como el Reportorio del indice de la nueva recopilación de las leyes del reyno, el cual da cuenta de la legislación española. Así mismo, en el acervo hubo varios libros del jurista británico Jeremy Benthan: Teoría de las recompensas, Teoría de las penas y un compendio de sus obras. Aparte, destaca el renombrado teólogo y político Joaquín Lorenzo Villanueva, quien aparece numerosas veces en el inventario (48 ejemplares de 5 títulos distintos), lo que denota interés de los ateneístas en las ciencias morales, una de las cátedras que impartían. Junto a las obras escritas por extranjeros, destacó una sobre la política del joven país: un facsímil de la edición príncipe de la Colección de Constituciones de los Estados Unidos Mexicanos; puede que hubiera menor cantidad de obras de este tipo debido a que esa nación, su política y constituciones apenas se estaban configurando. 
Entre los impresos literarios, destacan los diccionarios de italiano y francés, mismos que están relacionados con las cátedras de idiomas: Della lingua toscana (libri due), de Benedetto Bummattei y Nuevo diccionario frances-español, de Antonio Campany. Los libros de ciencia que aparecen en la lista tratan sobre física y matemáticas, siendo el matemático galés Silvestre-François Lacroix el más mencionado en el inventario; posiblemente, ello se deba a que los escritos de ese autor fueron unos de las más consultados en algunas ex colonias americanas durante el siglo XIX.

En el inventario también se mencionan libros sobre industria y agricultura, como la Investigación de la naturaleza y causas de la riqueza de las naciones, de Adam Smith, y el Curso completo, ó, Diccionario universal de agricultura teórica, de François Rozier. Es necesario destacar que hubo pocos libros sobre religión en comparación con los de otras materias; entre ellos, destaca la Sagrada Biblia (edición de Vence), la cual fue la primera versión de las sagradas escrituras producida en Hispanoamérica, ya que fue editada y vendida por el impresor y librero mexicano Mariano Galván.

La anterior clasificación muestra que, a pesar de la concordancia entre los temas de las cátedras y los tipos de libros de la biblioteca, algunas materias cobraron más relevancia que otras. Por ejemplo, hubo treinta y un títulos de historia, la misma cantidad de jurisprudencia y solo tres de religión. Ese contraste se debe a que el Ateneo Mexicano fue una institución republicana que respondía a las necesidades de la nación independiente, por lo que su contenido debía favorecer a la creación de un discurso nacional y la mejora política del país. En ese marco, los temas religiosos pasaron a un segundo plano.

En conclusión, conocer la colección de libros del Ateneo Mexicano nos permite aproximarnos a la cultura libresca de los ateneístas, quienes formaban parte de la élite política y económica de México, por lo que un análisis de caso sobre ese acervo permite observar cambios generales en la cultura libresca de la élite mexicana. Además de la variedad temática ya señalada, el origen extranjero de algunas obras invita a reflexionar sobre las condiciones del mercado de libro que hicieron posible su adquisición y la formación del Gabinete de Lectura, como son la desaparición 
de organismos de censura novohispanos que regulaban la importación de libros extranjeros, por ejemplo, la extinción del Tribunal del Santo Oficio, y el creciente interés de los libreros americanos en comerciar obras europeas. Por otra parte, el análisis de las características físicas de las ediciones o de su contenido (reimpresiones, versiones corregidas y aumentadas, libros con láminas o ilustraciones) posibilita conocer la preferencia de los lectores por cierto tipo de impresos para comprender los intereses de los bibliófilos mexicanos decimonónicos. Si bien se ha descrito de manera general el acervo bibliográfico de los ateneístas, se pueden examinar los títulos con mayor precisión en el inventario que se presenta a continuación. 
1849

[Foja 39] // Inventario de las obras pertenecientes al Estado de México que existían en el Ateneo y que ha entregado el Señor Don Ysidro Rafael Gondra.

A saber.

Tomo Obras

A

«1 Asuntos acordados (Perteneciente a la Nueva recopilación de Castilla)» [Consejo de Castilla de España, Reportorio del indice de la nueva recopilación de las leyes del reyno a cuya continuacion vá puesto el de los autos acordados. Madrid: Juan de Ariztia, 1723, folio].

«1 Astengo, Cartas de un presbítero espańol» [Lorenzo Astengo, Carta de un presbitero español. Madrid: Imprenta de Cano, 1798, folio].

«8 Annibal Caro, Sus obras» [No se encontraron compendios de obras del autor, sólo sus obras publicadas antes de 1849: Annibal Caro, Delle lettere familiari del commendatore Annibal Caro, 3 vol. Padua: Appresso Giuseppe Comino, 1742, 8º Opere del commendatore Annibal Caro, 8 vol. Milán: Società Tipografica de' Classici Italiani, 1807-1812, 4o ; Apología del commendatore Annibal Caro contra Lodovico Castelvetro: pubblicata dall'autore. Milán: Società Tipografica de' Classici Italiani, 1820, 4º; Scelta di lettere familiari. Milán: Giovanni Silvestri, 1825, 8 ; La rettorica d'Aristotile: libri tre. Fatta in lingua toscana dal commendatore Annibal Caro. Milán: Giovanni Silvestri, 1831, 8; Scelta di lettere familiari d'Annibal Caro fatta da Paolo Zanotti. E ora per la prima volta accresciuta, annotata, e a miglior lezione ridotta per cura e opera di Pietro dal Rio. Florencia: V. Batelli, 1846, 8º].

«23 Alfieri, Sus obras (El misogallo)» [Vittorio Alfieri da Asti, Il Misogallo: prose e rime. Londres: s. n., 1806, $8^{\circ}$ ].

"2 Biblioteca hispana nova» [Nicolás Antonio, Bibliotheca hispana nova sive Hispanorum scriptorm qui ab anno MD ad MDCLXXXIV floruere notitia. Madrid: Imprenta de Joaquín Ibarra, 1788, folio].

"2 Ydem id., Vetus» [Nicolas Antonio Hispalensi, Bibliotheca hispana vetus sive hispani scriptores qui ab Octaviani Augusti aevo ad annum Christi MD. floruerunt, 2 vols. Madrid: Imprenta de Joaquín Ibarra, 1788, folio]. 
«3 Ydem id., escurialende» [No se encontró ningún inventario de la Biblioteca del Escorial producido antes de 1849. La única obra del autor Nicolas Antonio Hispalensi que aún no ha sido mencionada en este inventario es: Bibliotheca Hispana sive Hispanorum qui usquam unquamve sive latiná sive populari ... scripto aliquid consignaverunt notitia ... : editorum atque ineditorum operum catalogum : duabus partibus continens. Roma: ex officina Nicolai Angeli Tinassii, 1672, folio].

«8 Bentham, Legislaciones» [Jeremy Bentham, Compendio de los tratados de legislación civil y penal. Notas por Joaquín Escriche, 2a ed. Madrid: Viuda de Calleja e hijos, 1839, 8º].

«2 Ydem id., Teoría de las recompensas» [Jeremy Bentham, Teoría de las recompensas, 2 vols. París: Imprenta de J. Smith, 1825, 8º].

«2 Ydem id., Teoría de las penas» [Jeremy Bentham, Teoría de las penas legales. París: Imprenta de J. Smith, 1825, 8º].

"9 Ydem id., Sus obras (Contienen lo siguiente: tratado de legislación, 3 tomos; Pruebas judiciales, 2 tomos; Penas y recompensas, 2 tomos; Asamblea legislativa, 2 tomos)" [Jeremy Bentham, Oeuvres de Jérémie Bentham, jurisconsulte anglais, $3^{\mathrm{a}}$ ed. Bruselas: Société Belge de Librairie, Imprenta de Hauman y Deltombe Gérant, 1840, folio].

«1 Becaria, Delitos y penas» [Cesare, Marchese di Beccaria, Tratado de los delitos $y$ de las penas, escrito en italiano por el Marqués de Becaria y traducido al castellano por Juan Rivera.Publicación. Madrid: Imprenta de Fermín Villalpando, 1821, 4º].

"2 Barbeijrac, Derecho national y de gente por Pufendorf.» [Samuel Pufendorf, Le droit de la nature et des gens, ou, Systeme general des principes le plus importants de la morale, de la jurisprudence, et de la politique, par le baron de Pufendorf, tr. Du latin par Jean Barbeyrac, 2 tomos, 5a ed. rev. Amsterdam: Chez la veuve de Pierre de Coup, 1734, folio].

«1 Burke, Revolución de Francia» [Edmund Burke, Reflexiones sobre la revolución de Francia, $2^{\mathrm{a}}$ ed., correg. y rev. por J.A.; trad. al castellano. México: Oficina a cargo de Martín Rivera, 1826, folio].

"1 [Burke], Indagación filosófica» [Edmund Burke, Indagación filosófica sobre el origen de nuestras ideas acerca de los sublime y lo bello, escrita en inglés ... y trad. al castellano por Juan de la Dehesa. Alcalá: Oficina de la Real Universidad, 1807, folio]. 
"1 Brisson, Diccionario universal de física» [Mathurin Jacques Brisson, Diccionario universal de fisica, escrito en francés por M. Brisson; trad. al castellano y aumentado con los nuevos descubrimientos posteriores a su publicación por los Doctores D.C.C. y D.F.X.C., 10 vols. Madrid: Imprenta de Benito Cano, 1796-1802, folio].

«1 Ydem id., Sus láminas.» [Vol. 10 del Diccionario universal de física, escrito en francés por M. Brisson; tr. al castellano y aumentado con los nuevos descubrimientos porteriores a su publicación por los Doctores D.C.C. y D.F.X.C., éste contiene las láminas del trabajo de Brisson].

"2 Bummattei, Della lingua toscana» [Benedetto Bummattei, Della lingua toscana, libri due, 2 vols. Milán: Dalla Societá Tipografica de'Classici Italiani, 1807, folio].

«12 Bembo, Opere» [Pietro Cardenal Bembo, Opere, 12 vols. Milán: Societá Tipografica de'Classici Italiani, 1808-1810, folio].

«4 Berni, Orlando innamorato» [Francesco Berni, Orlando innamorato. Londres: Livorno, Presso Gio Tommº. Masi e Comp., 1781, $8^{\circ}$ ].

«3 Benjamin Conttant, Curso de política» [Henri Benjamin Constant de Rebecque, Curso de política constitucional, escrito por Mr. Benjamin Constant, traducido libremente al español por D. Marcial Antonio López, 3 t., 2a ed. Burdeos: Imprenta de Lawalle Jóven, 1823, 8ㅇ․

«25 Biblia de Vence» [Sagrada Biblia, en latín y español, con notas literales, críticas, é históricas, prefacios y disertaciones, sacadas del Comentario de Agustin Calmet, Abad de Senones, del Abad Vence y de los más célebres autores, para facilitar la inteligencia de la Santa Escritura, 1a ed. mejicana, enteramente conforme a la 4 a y última francesa del año de 1820, 25 vols. México: Galván a cargo de Mariano Arévalo, 1831-1833, folio].

[Foja 39v] //

\section{C}

«2 Clavijero, Conquista de Mégico» [Francisco Javier Clavijero, Historia antigua de Megico: sacada de los mejores historiadores españoles y de los manuscritos, $y$ de las pinturas antiguas de los indios. Dividida en diez libros ..., 2 vol., trad. del italiano por José Joaquín de Mora. Londres: R. Ackermann, 1826, folio]. «37 Concilios» [No se identificó la obra]. 
«1 Cabarrus, Cartas» [Francisco Cabarrús, Cartas del conde de Cabarrus al Señor D. Gaspar de Jovellanos, sobre los obstáculos que la naturaleza, la opinión y las leyes oponen a la felicidad pública. Burdeos: Lawalle joven y sobrino, 1820, 8º].

«3 Ydem id., Código de Napoleón» [Código Napoleón: con las variaciones adoptadas por el cuerpo legislativo el dia 3 de septiembre de 1807. Madrid: Imprenta de la hija de Ibarra, 1809, folio].

«3 Cicerón, Diálogos de.. (Sólo el tomo 2)» [Los dialogos de Ciceron de la vejez, de la amistad, las paradoxas, y el sueño de escipion, trad. de Manuel de Valbuena. Madrid: en la Imprenta Real, 1788, $8^{\circ}$ ].

«3 Colección de Constituciones de la República» [Colección de Constituciones de los Estados Unidos Mexicanos. Régimen constitucional 1824. Facsímil de la edición príncipe, 3 vols. México: Imprenta de Mariano Galván Rivera, 1828, folio].

«3 Chiabrera Mine» [Gabriello Chabrera, Opere di Gabriello Chiabrera e di Fulvio Testi, 1834. Milán: Nicolò Bettoni, 1834, folio].

$\mathrm{D}$

«1 Diccionario inglés-español Delfino» [No se identificó la obra].

«3 Ydem id., De comercio» [Ardoin, Diccionario Universal del Comercio, de la banca, de las manufacturas, y de las mercaderias: contiene el estado actual del comercio y de la industria de todas las naciones comerciantes y de las principales plazas mercantiles de todas las partes del mundo..., por Ardoin. [et. al.], traducido y aumentado por Antonio Pérez Domingo, 2 vols. Málaga: Imprenta de Martínez de Aguilar, 1845-1846, folio].

«2 Ydem id., Francés-español por Gattel.» [Antonio Campany, Nuevo diccionario frances-español: en este van enmendados, corregidos, mejorados, y enriquecidos considerablemente los Gattel, y Cormon, por Antonio Capmany, 2a ed. Madrid: Imprenta de Sancha, 1817, 40 $]$.

«3 D' Alembert, Obras» [Jean Lerond D'Alembert, Oeuvres de d'Alembert, 5 vols. París: A. Berlin, Bossange pére et flls, 1821-1822, 4ํ].

«20 Discursos pronunciados en la tribuna de la Francia» [No se identificó la obra].

«4 De la casa opere» [No se identificó la obra]. 
«1 Domat, Leyes civiles de Francia» [Jean Domat, Las leyes civiles en su orden natural, obra escrita en francés por $J$. Domat y arreglada para el uno de los españoles por Felio Villarrubias y José Sarda, 2a ed. Barcelona: Imprenta de José Taulo, 1844, 4º].

«3 Flores, Medallas de España» [Enrique Flórez, Medallas de las colonias, municipios y pueblos antiguos de España. Colección de las que se hallan en diversos autores, $y$ de otras nunca publicadas: con explicación y dibujo de cada una. Por el R. P. M. Fr. Henrique Flores, del Orden de San Agustín, Catedrático de Teología de la Universidad de Alcalá, y Exprovincial de su Provincia de Castilla. Madrid: Oficina de Antonio Marín, 1773].

«43 Ydem id., España sagrada» [Enrique Flórez, España sagrada, theatro geographico-historico de la iglesia de España: origen... de todas sus provincias, antigüedad, traslaciones y estado antiguo y presente de sus sillas en todos los dominios de España y Portugal... Madrid: s. n., 1748, 4º].

"2 Ydem id., Memorias de las Reinas de España» [Enrique Flórez, Memorias de las reynas catholicas, historia genealógica de la casa real de Castilla, y de León, todos los infantes: trajes de las reynas en estampas: y nuevo aspecto de la historia de España, 2 vols., 2a ed., Madrid: Antonio Marín, 1770, 4º].

«1 Ydem id., Clave historial» [Enrique Flórez, Clave historial: con que se abre la puerta a la historia eclesiástica y politica, chronología de los Papas y Emperadores, Reyes de España, Italia y Francia, con los orígenes de todas las monarquias, concilios, herejes, santos, escritores y sucesos memorables de cada siglo, 15a ed. Madrid: Imprenta de la Viuda de Ibarra, 1798, 4º].

«6 Filangieri, Legislación» [Gaetano Filangieri, Ciencia de la legislación, por el caballero Caetano Filangieri, nuevamente traducida por Don Juan Ribera, $2^{\mathrm{a}} \mathrm{ed}$. rev. Burdeos: Imprenta de Pedro Beaume, 1823, 8º].

«2 Ydem id., Comentarios» [Gaetano Filangieri, Ciencia de la legislación, por el caballero Caetano Filangieri, nuevamente traducida por Don Juan Ribera, 2a ed. rev. Burdeos: Imprenta de Pedro Beaume, 1823, $8^{\circ}$ ].

«36 Fleuri, Historia eclesiástica» [Claude Fleury, Abad de Loc-Dieu, Histoire ecclésiastique, par M. Fleury., Edición Rev. \& corr. par l'auteur. Paris: Chez les Libraires Associés, 1774, 8º].

«4 Firenzuola, Ópere» [Agnolo Firenzuola, Opere di messer Agnolo Firenzuola, 5 vols. Milán: Societá Tipografica de Classici Italiani, 1802, 4º]. 
G

«2 Gracián, Obras» [Baltasar Gracián, Obras de Lorenzo Gracián, 2 vols. Madrid: Pedro Marín, 1773, 4º].

"6 Gioja, Ciencia económica» [Melchiore Gioja, Nuovo prospetto delle scienze economiche ossia somma totale delle idee teoriche e pratiche in ogni ramo d'amministrazione privata e pubblica, divise in altrettante classi, unite in sistema ragionato e generale, 6 vols. Milán: Presso Gio. Pirotta in Santa Radegonda, Giugno, 1815, folio].

«1 Gravina, Obras» [Giovanni Vincenzo Gravina, Opuscula et orationes varii argumenti, seu, Operum. Lipsiae: Ex Officina Georgii Saalbachii, ca. 1700, folio; Opere italiane: si sono aggiunte alcune lettere latine dell'istesso autore. Nápoles: Giuseppe Raimondi, 1757, folio; Opera, seu, Originum juris civilis: libris tres, 3 vols. Venecia: Franciscum Pitteri, 1758, folio; Opere scelte. Milán: Società Tipografica de' Classici Italiani, 1819, folio].

«3 Groccio, Derecho de la guerra y de la paz» [Hugo Grotius, Le droit de la guerre et de la paix, 3 vols. Amsterdam: Abraham Wolfang, 1688, $12^{\circ}$ ].

[Foja 40] //

«3 Gelli, La Circe» [Giovanni Battista Gelli, La Circe, testo di lingua ora novamente emendato. Venecia: Tipographia di Alvisopoli, 1825, 8º].

"2 Goldsmith, Compendio de la historia romana» [Oliver Goldsmith, Compendio de la historia romana, 2 vols., $2^{\text {a }}$ ed., trad. del inglés. Madrid: Casa de Rosa, $1822,8^{\circ}$ ].

\section{$\mathrm{H}$}

«5 Herrera, Historia de Yndias» [Antonio de Herrera y Tordesillas, Historia general de las Indias Occidentales, o De los hechos de los castellanos en las islas, y tierra firme del mar océano, 4 vol. Amberes: Imprenta de Juan Bautista Verdussen, 1728 , folio].

«9 Heinecio, Sus obras» [Johann Gottlieb Heineccius, Recitaciones del Derecho civil, traducidas al castellano, anotadas y adicionadas considerablemente por Luis de Collantes y Bustamant, 3 vol., $3^{\text {a }}$ ed. Valencia: Imprenta de Cabrerizo, 1841, 8º].

«1 Hericort, Leyes eclesiásticas de Francia» [Se describirá la segunda edición de la obra publicada en 1853, pero la primera edición posiblemente fue publicada años anteriores a la elaboración del inventario: Luis de Hericourt 
Leyes eclesiásticas de Francia puestas en su orden natural, refundida en el código eclesiástico francés, traducida por Don Epifanio Díaz Iglesias Castañeda, 2a ed., Madrid: Imprenta de Ancos, 1853, 8º].

«3 Heloccia, Obras» [No se identificó la obra].

"1 Jovellanos, Ley agraria» [Gaspar Melchor de Jovellanos, Informe de D. Gaspar de Jovellanos en el expediente de Ley Agraria. Madrid: s. n., 1820, 8º].

$\mathrm{L}$

«1 Lacroix, Tratado del cálculo diferencial e integral» [Silvestre François Lacroix, Traité élémentaire de calcul différentiel et de calcul intégral, 4e éd., rev., corr. et augm. Paris: Bachelier (Successeur de Mme Ve Courcier) Librairie Parisienne, $\left.1828,4^{\circ}\right]$.

«2 Ydem id., Álgebra» [Silvestre-François Lacroix, Tratado elemental de álgebra, s.l., s. n., s.a., $4^{\mathrm{o}}$; y Curso completo elemental de matemáticas puras, tomo II, Álgebra, trad. de Josef Rebollo y Morales. Madrid: Imprenta Real, 1821, $4^{\circ}$ ].

"2 Ydem id., Geometría» [Silvestre-François Lacroix, Elementos de geometría, traducida por Don Josef Rebollo y Morales, Catedrático de los Caballeros Pages de S.M., 10 ed. Madrid: Imprenta Real, 1819, 4º].

«1 Ydem id., Trigonometría» [Sylvestre-Francois Lacroix, Tratado elemental de trigonometría rectilinea y esférica, y de la aplicación del álgebra a la geometría, traducida por los catedráticos de matemáticas de los Caballeros Pages de S.M., 7a ed. Madrid: Imprenta Real, s.a., $4^{\circ}$ ].

«1 Ydem id., Cálculo de probabilidades» [Silvestre François Lacroix, Traité élementaire du calcul des probabilités, 2e ed., rev. y aumentada. París: Bachelier, $\left.1822,4^{\circ}\right]$.

«15 La Harpe, Curso de literatura (falta el último tomo)» [Jean-François de la Harpe, Cours de littérature ancienne et moderne, suivi du tableau de la littérature au XIX e, siécle, par Chénier, et du tableau de la littérature au XVIe, siécle, par Saint-Marc Gorardin, et Philarete Chasles. París: Firmin Didot, 1840, folio].

«24 Ydem id., Viajes con atlas» [No se encontró alguna obra de La Harpe que lleve por título Viajes con Atlas. Sin embargo, uno de sus libros, Compendio de historia general de los viajes, comprende un Atlas con un registro completo de 
los viajes del autor a lo largo de su vida: Jean-François de la Harpe, Compendio della storia generale: déviaggi .., Venecia: Rinaldo Benvenuti, 1781, 4º].

LL

«4 Llorente, Provincias vascongadas» [Juan Antonio Llorente, Noticias históricas de las tres provincias vascongadas, Alava, Guipuzcoa y Vizcaya, Parte III, tomo IV. Madrid: Imprenta Real, 1808].

«10 Ydem id., Historia crítica de la Inquisición» [Juan Antonio Llorente, Historia crítica de la Inquisición de España: obra original conforme a lo que resulta de los Archivos del Consejo de la Suprema y de los Tribunales de provincia, 8 vols. Barcelona: Imprenta de Oliva, 1835-1836, 8º].

"2 Ydem id., Anales de la Inquisición» [Juan Antonio Llorente, Anales de la Inquisición de España, 2 vol., Madrid, Imprenta de Ibarra, 1812-1813, 8º; Anales de la Inquisición: desde que fue instituido aquel Tribunal, hasta su total estinción en el año de 1834. Madrid: 1841, 40 ${ }^{\circ}$.

«1 Ydem id., Observaciones de Gil Blas» [Juan Antonio Llorente, Observaciones criticas sobre el romance de Gil Blas de Santillana: en las cuales se hace ver que Mr. Le Sage lo desmembró del de El Bachiller de Salamanca, entonces manuscrito español inédito: y se satisface a todos los argumentos contrarios publicados por el Conde de Neufchateau. Madrid: Imprenta de Tomás Albán, 1822, 8º].

M

«6 Maltebrun, Geografía» [Conrad Malte-Brun, Geografía universal o Descripción de todas las partes del mundo, por el célebre Malte-Brun; puesta al corriente de la ciencia y completado lo que correspone a España y sus colonias por D.M.B.Y P., 7 vols. Madrid: Barcelona, Imprenta de Luis Tasso, ca. 1848, folio].

«1 Ydem id., Atlas» [Conrad Malte-Brun, Atlas. Madrid: Laureani Gimeno impresor, s.a., folio; Atlas complet du précis de la géographie universelle de MalteBrun [Material cartográfico], dressé conformément au texte de cet ouvrage et entièrement revu et corrigé par J.-J.-N. Huot. Bruselas: Lacrosse et Cie., LibrairesÉditeurs ..., 1839, folio, 71 mapas].

"15 Mabli, Sus obras (faltan 34)» [Llama la atención que dice: faltan 34, es poco probable que se trate de una obra de 49 tomos (15 que tenían más 34 que faltaban), quizá era una obra de la que tenían muchos ejemplares: Gabriel Bonnot de Mably, Collection complete des oeuvres de l'abbé de Mably, 15 vols. París: De l'imprimerie de Ch. Desbriere, 1794-1795, 4º; Oeuvres posthumes 
de L'Abbé de Mably, 3 vols. París: Chez Guillaume, de l'imprimerie de Ch. Desbriere, $\left.1798,4^{\circ}\right]$.

«2 Magalotti, Ópera» [Lorenzo Conde Magalotti, Delle opere. Milán: Societá Tipografica de'Classici Italiani, 1806, folio].

«1 Menzini, Poeizé» [Benedetto Menzini, Poesie di Benedetto Menzini...divise in due Torni, tomo I. Niza: Presso la Societá Tipografica, 1782, 16º].

«3 Michaude, Árboles de América» [No se identificó la obra].

\section{$\mathrm{N}$}

«1 Navarrete, Viajes» [Martín Fernández de Navarrete, Colección de los viajes $y$ descubrimientos que hicieron por mar los españoles desde fines del siglo XV: con varios documentos inéditos concernientes a la historia de la marina castellana y de los establecimientos españoles en Indias, coordinada e ilustrada ..., 5 vols. Madrid: Imprenta Real, 1825-1837, 40․

"2 Nueva recopilación» [Consejo de Castilla, Reportorio del indice de la nueva recopilación de las leyes del reyno a cuya continuacion va puesto el de los autos acordados. Madrid: Juan de Aritzia, 1723, folio].

«1 Newton, Aritmétrica» [Isaac Newton, Arithmetica universalis Isaaci Newtoni, sive, De compositione et resolutione arithmetica perpetuis commentariisillustrata et aucta, s.l., Ex Typographia Bibliothecae Ambros, 1752, 4º].

"2 Nuevo viaje pintoresco a Francia» [Thomas Frognall Dibdin; Georges Adrien Crapelet; François Isidore Licquet; Antoine Augustin Renouard, Voyage Bibliographique, Archéologique Et Pittoresque En France Tome Troisième. Paris: Crapelet Paris Renouard, 1825, $8^{\circ}$.

[Foja 40v]// P

«3 Partidas del Rey Don Alfonso» [Gregorio López de Tovar (ed.), Las siete partidas del sabio rey Don Alonso el Nono, glosadas por el licenciado Gregorio López, Decimosexta y última edición, Madrid, en la Oficina de Nenito Cano, año de MDCCLXXXIX (1789). Madrid: Impresor Cano Benito, 1542-1596].

«2 Pausanias, Historia» [Pausanias, Ou voyage historique de la Grece, 4 ts. París: Chez Jean-Francois Bastien, 1793, $8^{\circ}$ ].

«25 Plutarco, Sus obras» [Plutarco, Oeuvres morales de Plutarque, traduites du gree par Ricard. París: Didier, 1844, 8º]. 
«1 Passy, De la aristocracia» [Se encontraron dos ediciones de la obra, una escrita en idioma francés, otra en inglés: Hippolyte Philibert Passy, De l'aristocratie considérée dans ses rapports: avec les progrès de la civilisation, par $M . H$. Passy, Paris, A. Bossange, 1826, 40; Aristocracy, considered in its relations with the progress of civilization. London: A. Hall London, A. Hall \& Co., 1848].

«130 Petitot, Memorias de la revolución de Francia (falta el tomo 44 de la segunda serie)" [Claude Bernard Petitot, Collection complète des mémoires relatifs a l'histoire de France: depuis le règne de Philippe-Auguste, jusqu'au commencement $d u$ dix-septième siècle / avec des notices sur chaque auteur, et des observations sur chaque ouvrage, par M. Petitot Les mémoires de Mémoires de Messire Martin du Bellay. Paris: Foucault, 1821, 4º].

«1 Poliziano» [Angelo Poliziano, Conjurationis Pactianae anni MCCCCLXXVIII. Commentarium. Documentis, figuris, notis nunc primum inlustratum cura, et studio Ioannis Adimari, [Nápoles]: J. Adimari, 1769, folio].

"7 Polive, Historia» [Polibio, Histoire, nouvellement traduite du grec par Dom Vincent Thuillier, Bénédictin ... ; avec un commentaire ou un corps de science militaire, enrichi de notes ... par $M$. de Folard ... , tome second. Amsterdam: chez Arkstée et Merkus, 1774, 4º].

\section{Q}

«1 Quinto Curio» [Quintus Curtius Rufus, De la vida y acciones de Alexandro el Grande, 2 vol., trad. de la lengua latina a la española por Mateo Ibañez de Segovia y Orellana. Madrid: librería de la viuda de Hernando y c.a., 1887-1888, $8^{\circ}$ ].

$\mathrm{R}$

"11 Restrepo, Revolución de Colombia con Atlas» [No se encontró alguna obra de José Manuel Restrepo que lleve por título Revolución de Colombia con Atlas; sin embargo, la siguiente edición se aproxima porque en su contenido incluye textos y mapas: José Manuel Restrepo, Historia de la revolución de la República de Colombia, 11 vols. París: Librería Americana, 1827, Imprenta de David, 80].

«12 Rozier, Curso de agricultura» [Rozier, Curso completo, o, Diccionario universal de agricultura teórica, práctica, económica, y de medicina rural y veterinaria / escrito en francés por una sociedad de agronomos y ordenado por el abate Rozier; 16 vols., trad. al castellano por Don Juan Álvarez Guerra. Madrid: Imprenta Real, 1797-1803, 40 $]$. 
«8 Real ciencia del Gobierno» [El inventario no precisa el nombre del autor, o alguno de sus apellidos; por tal motivo, no fue posible encontrar con exactitud esta obra. Uno de los libros sobre política, frecuentemente consultados en el siglo XIX fue el siguiente: Gaspar de Réal de Curban, , La ciencia del gobierno, obra de moral, de derecho, y de politica, que comprehende los principios del mando, y de la obediencia, en qué se reducen todas las materias de gobierno à un cuerpo único, entero en cada una de sus partes, y en donde se explican los derechos, y obligaciones de los soberanos, de los vasallos, y de los hombres in qualquiera estado, en qué se hallan, trad. al español por Mariano Joseph Sala, Solanes de Llunell, con algunas notas críticas por el mismo traductor, Barcelona, C. Gibert y Tutó, 1775, 4ㅇ․.$^{55}$

"5 Smith, Riqueza de las naciones» [Adam Smith, Investigación de la naturaleza y causas de la riqueza de las naciones, 4 vol., $2^{\text {a }}$ ed. corregida, trad. al castellano por Josef Alonso Ortiz. Valladolid: Oficina de la viuda e hijos de Santander, $\left.1805-1806,16^{\circ}\right]$.

«2 Sarpi, Historia del Concilio de Trento» [Paolo Sarpi, Istoria del Concilio Tridentino, con note critiche, istoriche e teologiche Di Pietro Francesco Le Courayer, 2 vols. Londres: Allespese de Fratelli de Tournes, 1757, folio].

"5 Say, Curso de economía política (esta obra sólo consta de tres tomos» [Jean-Baptiste Say, Principios de economía política o instrucción familiar en forma de diálogo. Madrid: Imprenta Real, 1816, 8º].

«30 Según: Obras (faltando los tomos 7 y 8)» [No se encontró a ningún autor con el apellido Según; por lo tanto, se desconoce a qué obra se refería el escribano. También podría referirse al autor francés Édouard Séguin, pero no hay compendios de sus obras].

«1 [Según], Atlas» [No se encontró ningún Atlas escrito por fray Bernardino de Sahagún, ni por Édouard Séguin].

\section{$\mathrm{V}$}

«1 Villanueva, Kempis de los literatos» [Joaquín Lorenzo Villanueva, El Kempis de los literatos. Madrid: Imprenta Real, 1807, 8º].

55 Aguilar 1993: 714 . 
"1 Ydem id., De la obligación de decir la misa» [Joaquín Lorenzo Villanueva, De la obligación de decir misa con circunspección y pausa. Madrid: Imprenta Real, 1788, 8º].

"10 Ydem id., Viaje literario a las iglesias de Espańa» [Jaime Villanueva, Viage [sic] literario a las iglesias de España; le publica con algunas observaciones Joaquin Lorenzo Villanueva, 22 vols. Madrid: Imprenta Real, 1803-1852, 4º].

«1 Ydem id., Catecismo del Estado» [Joaquín Lorenzo Villanueva, Catecismo del Estado: según los principios de la religión. Madrid: Imprenta Real, 1793, 4º].

«1 Ydem id., Cartas eclesiásticas» [Joaquín Lorenzo Villanueva, Cartas eclesiásticas de D. Joaquin Lorenzo Villanueva al doctor D. Guillermo Díaz Luzeredi en defensa de las leyes que autorizan ahora al pueblo para que lea en su lengua la Sagrada Escritura: Va al principio una carta del Rmo. P. Felipe Scio de S. Miguel ... á este mismo propósito. Madrid: Real Imprenta, 1794, 4º].

"1 Ydem id., Concordato de México con Roma» [Joaquín Lorenzo Villanueva, Juicio de la obra del señor arzobispo Depradt intitulada Concordato de Méjico con Roma por el Doctor Joaquin Lorenzo Villanueva. Londres: Imprenta de A. Macintosh, $1827,8^{\circ}$ ].

«2 Ydem id., Su vida literaria» [Joaquín Lorenzo Villanueva, Vida literaria de Dn. Joaquin Lorenzo Villanueva, o, Memoria de sus escritos y de sus opiniones eclesiásticas y politicas, y de algunos sucesos notables de su tiempo, 2 vols. Londres: Dulau y Compañía, 1825, 4ㅇ․

«1 Ydem id., De la lección de la sagrada escritura» [Joaquín Lorenzo Villanueva, De la lección de la sagrada escritura en lenguas vulgares, calificador del Santo Oficio. Valencia: Oficio de Benito Monfort, 1791, folio].

«43 Viajero universal» [No se identificó la obra].

«1 Vouglans, Leyes criminales de Francia» [Pierre Francois Muyart de Vouglans, Les loix criminelles de France, dans leur ordre natural. París: Merigot le jeune, Crapart, Benoît Morin, 1780, folio].

"1 Zurita, Annales de Aragón» [Gerónimo Zurita y Castro, Anales de la corona de Aragón, compvestos por Geronymo Çvrita, chronista de dicho reyno, 7 vols. Zaragoza: Colegio de S. Vicente Ferrer, 1610, folio].

Ignacio Flores Pemado [rubricado]

Ceferino Barajas [rubricado] 


\section{BIBLIOGRAFÍA}

Aguilar Piñal, Francisco. 1993. Bibliografía de autores españoles del s. XVIII. Tomo VII. Madrid: Consejo Superior de Investigaciones Científicas.

Alamán, Lucas. 1844. «Interior. Prospecto. Disertaciones sobre la historia de la República mexicana, desde la época de la conquista que los españoles hicieron a fines del siglo XV y principios del siglo XVI, de las islas y continente americano hasta la independencia, por D. Lucas Alamán». Diario del Gobierno de la República Mexicana. Ciudad de México, 4 de julio: 259. Anónimo. 1841. «El Ateneo Megicano [...]». Semanario de la Industria Mexicana. Ciudad de México, 15 de junio: 70.

Anónimo. 1843a. «El Ateneo mexicano, en junta general que ha celebrado ayer, bajo la dirección de su digno presidente el Exmo. Sr. ministro de guerra, general D. José María Tornel, ha acordado se abra su sala de lectura». Diario del Gobierno de la República Mexicana. Ciudad de México, 10 de abril: 464. Anónimo. 1843b. «Se participa a los individuos del Ateneo Mexicano». Diario de la República Mexicana. Ciudad de México, 4 de julio: 256.

Anónimo. 1843c. «El domingo en la noche se han verificado los ecsamenes privados de aritmétrica de la cátedra de matemáticas, dirigida en el Ateneo Mexicano, por D. Benito Leon Acosta». Diario del Gobierno de la República Mexicana. Ciudad de México, 7 de noviembre: 275.

Anónimo. 1844a. «México, 27 de febrero de 1844». Diario del gobierno de la República Mexicana. Ciudad de México, 1 de marzo: 243.

Anónimo. 1844b. «Variedades. Bibliografía. Concluye el estracto de la obra titulada: MÉXICO EN 1842, por D. Luis Manuel del Rivero, ILUSTRACION». El Siglo Diez y Nueve. Ciudad de México, 15 de noviembre: 2.

Anónimo. 1845. «Elecciones». El Monitor Constitucional. Ciudad de México, 4 de febrero: 4.

Anónimo. 1849. «Parte literaria. Importancia de la historia. La historia en México». El Siglo Diez y Nueve. Ciudad de México, 25 de enero: 99.

Arnabat Mata, Ramón. 2012. «Evolución histórica de los Ateneos en Cataluña (1836-1936)». Historia Contemporánea. Número 55: 383-420.

Arroyo, José María. 1843a. «Remitidos. Ateneo Mexicano». Diario del Gobierno de la República Mexicana. México, 17 de enero: 127.

Arroyo, J. Miguel. 1843b. «Ateneo Mexicano». Diario del Gobierno de la República Mexicana. Ciudad de México, 2 de agosto: 376.

Ateneo Mexicano. 1844. «Remitidos. Ateneo Mexicano». Diario del Gobierno de la República Mexicana. 5 de abril: 382. 
Ateneo Mexicano. 1848. «Hoy ha salido a la luz el número 1 de El Ateneo Mexicano». Diario del Gobierno de la República Mexicana. Ciudad de México, 25 de marzo: 340 .

Azuela, Luz Fernanda. 2018. «La ciencia en la esfera pública mexicana (1821-1864)». Saberes. Revista de historia de las ciencias y las humanidades. Volumen 1, número 3, vol. 1, enero-junio:30-56.

Bello, Kenia. 2017. «Una biblioteca para artistas. La Academia de San Carlos y la lectura pública (1785-1843)». En Sánchez de la Torre, Laura (coord.). Estantes para impresos. Espacios para lectores. Siglos XVIII-XIX. Ciudad de México: Instituto Mora, 215-248.

Bergara, B. 1841. "Ateneo Mexicano». El Siglo Diez y Nueve. Ciudad de México, 27 de octubre: 4.

Beyer K., Walter O. 2016. «La influencia de Sylvestre-François Lacroix en la matemática venezolana decimonónica». Revista de História de Educação da Matemática. Volumen 2, número 3: 229-255.

Cabrera Quintero, Conrado Gilberto. 2005. La creación del imaginario indio en la literatura del siglo XIX. Ciudad de México: Benemérita Universidad Autónoma de Puebla, Dirección General de Fomento Editorial.

Colón, Cecilia. 2009. «La construcción de la literatura nacional». Estudios humanísticos. Volumen 21, número 38: 93-100.

Cortéz, María Fernanda Gloria. 2019. El papel del bibliotecario en la Pública Real Biblioteca (Real Universidad de México), 1761-1810. Tesis de licenciatura en Historia. Ciudad de México: Universidad Nacional Autónoma de México.

Cortés Zavala, María Teresa. 2016. «La sociedad económica de amigos del país en Puerto Rico y las prácticas de lectura en el primer gabinete de lectura». Revista Brasileira do Caribe. Volumen 17, número 32: 99-131.

De la Guardia Herrero, Carmen. 2005. «Sociedades, casinos y ateneos. «La emergencia de la esfera pública en América Latina y España». Acta Académica, Universidad Nacional del Rosario. X Jornadas Interescuelas/ Departamentos. Mesa 67: 1-13.

E.E. de la Hesperia. 1842. "Interior», México, Noviembre 5 de 1842. Interés General». Diario del Gobierno de la República Mexicana. Ciudad de México, 7 de noviembre: 391.

E.E. del Estandarte. 1843. «Idem 12 del Idem». Diario del Gobierno de la República Mexicana. Ciudad de México, 14 de abril: 478.

El observador. 1842. «Remitido». El Siglo Diez y Nueve. Ciudad de México, 20 de febrero: 2 .

Esteban, Vicente A. 1843. «Ecsamenes públicos del Instituto de Ntra. Señora del Refugio». El Siglo Diez y Nueve. Ciudad de México, 23 de diciembre: 2. 
García López, Genaro Luis y Olga María López Álvarez. 2004. «La génesis de las bibliotecas universitarias en España». Investigación bibliotecológica. Número 38: 61-76. https://doi.org/10.22201/iibi.0187358xp.2005.38.4062

Gómez de la Cortina, José. 1842. «Señores editores del Diario». Diario del Gobierno de la República Mexicana. Ciudad de México, 27 de noviembre: 476.

Gondra, Rafael Isidro. 1844. «Literatura. El orador en el púlpito-Elocuencia sagrada». Diario del Gobierno de la República Mexicana. Ciudad de México, 7 de junio: 152.

Lafragua, José María. 1844a. «Ateneo Mexicano». El Siglo Diez y Nueve. Ciudad de México, 24 de febrero: 2.

Lafragua, José María. 1844b. «Ateneo Mexicano». El Siglo Diez y Nueve. Ciudad de México, 4 de junio: 4.

Lafragua, José María. 1844c. «Remitidos. Ateneo Mexicano». El Siglo Diez y Nueve. Ciudad de México, 9 de junio: 3.

Lafragua, José María. 1844d. «Ateneo Mexicano». El Siglo Diez y Nueve. Ciudad de México, 13 de marzo, 5 de mayo, 15 de abril, 28 de abril, 5 de julio: 4 .

Lafragua, José María y Vergara, Pablo. 1843. «Ateneo Mexicano». Diario del Gobierno de la República Mexicana. Ciudad de México, 24 de abril: 519.

Lahirigoyen. María Trinidad. 2005. Catálogo del Archivo Histórico. Volumen IV. Ciudad de México: Museo Nacional de Antropología, Instituto Nacional de Antropología e Historia: 7-15.

Mexicano. 1843. «Bibliotecas públicas». Diario del Gobierno de la República Mexicana. Ciudad de México, 1 de septiembre: 3 .

Ministerio de Relaciones Exteriores y Gobernación. 1842. «Resumen de las providencias dictadas por el Supremo gobierno de la República, durante el mes de Octubre». Diario del Gobierno de la República Mexicana. Ciudad de México, 2 de noviembre: $370-371$.

Perales Ojeda, Alicia. 2017. «El Ateneo Mexicano». En Secretaría de Cultura, Fundación para las Letras Mexicanas, Enciclopedia de Literatura en México, nov. 2017: <http://www.elem.mx/estgrp/datos/122>.

Ramírez Aledón, Germán. 2009. "Joaquín Lorenzo de Villanueva, un clérigo en la encrucijada de la revolución liberal». En Callado Estela, Emilio (coord..). Valencianos en la historia de la Iglesia III. Valencia: Facultad de Teología San Vicente Ferrer, 315-354.

Sabas Silva, Ana Lilia. 2010. "Una aproximación al asociacionismo científico de la primera mitad del siglo XIX. El caso de la Historia Natural y la Geografía en el Ateneo Mexicano». En Lértora Mendoza, Cecilia A. (coord.). GEONATURALIA. Geografia e Historia Natural: hacia una historia comparada. Estudio a través de Argentina, México, Costa Rica y Paraguay. Buenos Aires: Ediciones F.E.P.A.I., 91-129. 
Salas Álvarez, Jesús. 2009. «La antigüedad clásica en la España Sagrada del Padre Henrique Flórez de Setién y Huidobro». Gerión. Volumen 27, número 2: 57-78. Sánchez Moguel, A. 1892-1893. «Las Conferencias americanistas del ateneo». El centenario: Revista ilustrada. Tomo I: 129-136.

Solares Robles, Laura. 2001. «Prosperidad y quiebra. Una vivencia constante en la vida de Mariano Galbán Rivera». En Suárez de la Torre, Laura y Miguel Ángel Castro (coords.). Empresa y cultura en tinta y papel (1800-1860). Ciudad de México: Instituto de Investigación Dr. José María Luis Mora, 109-121.

Suárez, Manuel. 2014. «Acomodar, ordenar y leer. La disposición de los libros en los acervos novohispanos durante la segunda mitad del siglo XVIII». Brazilian Journal of Information Design. Volumen 11, número 2: 185-200. https://doi. org/10.51358/id.v11i2.322

Suárez, Manuel. 2020. La Alhaja más preciosa: historia de la Biblioteca de la Real Universidad de México (1761-1813). Ciudad de México: Universidad Nacional Autónoma de México, Instituto de Investigaciones Bibliográficas (en prensa).

Urías, Beatriz. 1988. «Educación para la democracia: El Ateneo Mexicano (18401851)». Estudios historial filosofial letras. Número 12: 29-52. https://doi.org/1 $0.5347 / 01856383.0012 .000170313$

Valentín, Miguel. 1841. «Discurso que en la solemne apertura del Ateneo Mexicano, pronunció su presidente el Sr. Dr. D. Miguel Valentín». La Hesperia, 23 de enero: 3 .

Velez. 1842. «Considerando el Escmo. Sr. presidente provisional, la importancia del establecimiento literario». El Siglo Diez y Nueve. Ciudad de México, 3 de noviembre: 3 .

Vergara, Pablo. 1841. «Ateneo Mexicano». El Cosmopolita. Ciudad de México, 28 de julio: 4 .

Vergara, Pablo. 1843. "Avisos. Ateneo Mexicano». Diario del Gobierno de la República Mexicana. Ciudad de México, 13 de abril: 476.

Villacorta Baños, Francisco. 2003. «Los Ateneos liberales: política, cultura y sociabilidad intelectual». Revista Hispania. Número 214: 415-442. https://doi. org/10.3989/hispania.2003.v63.i214.218

Zirea, Miguel y Gómez de la Cortina, José. 1841. «México. Secretaría del gobierno del Departamento de México». El Siglo Diez y Nueve. Ciudad de México, 6 de noviembre: 2 .

Zurutuza, A. y De Veraza, J. N. 1842. «Avisos. Ateneo Mexicano». El Siglo Diez y Nueve. Ciudad de México, 26 de abril: 4.

Fecha de recepción: 16/X/2020

Fecha de aceptación: 2/XI/2020 